\title{
The Potential Effect of Anthropogenic Salinization and Ocean Acidification on Lightning Flash Intensity Over the Mediterranean Sea
}

\author{
Mustafa Asfur ${ }^{1 *}$ and Jacob Silverman ${ }^{2}$ \\ ${ }^{1}$ Faculty of Marine Sciences, Ruppin Academic Center, Mikhmoret, Israel \\ ${ }^{2}$ National Institute of Oceanography (IOLR), Tel Shikmona, Haifa, Israel \\ ${ }^{\star}$ Corresponding author: Mustafa Asfur, Faculty of Marine Sciences, Ruppin Academic Center, Mikhmoret, Israel; Email: mustafaa@ruppin.ac.il
}

Received: November 09, 2021; Accepted: November 15, 2021; Published: November 26, 2021

\begin{abstract}
In the last century the Mediterranean Sea has undergone significant changes due to the effects of global and regional anthropogenic changes. Global warming and the erection of the Aswan High Dam (AHD) have caused substantial changes in the chemical and physical properties of seawater. The combined effects of these changes resulted in salinization of Levantine Surface Waters (LSW) from 38.95 to 39.4 since the erection of the AHD. During the same period the increase of atmospheric $\mathrm{CO}_{2}$ resulted in ocean acidification (OA) of LSW on the order of $-0.1 \mathrm{pH}$ units. Based on these experimental results we estimate that Lightning Intensity in the LSW may have increased by as much as $12 \%$ since the 1960's. Furthermore, assuming that salinization and acidification of LSW will continue at current trends, the Lightning Intensity is predicted to increase by $23 \%$ relative to the pre 1960 's by 2050 .
\end{abstract}

Plain Language Summary

In our previous studies we showed based on laboratory experiments that cloud to ocean surface electrical discharges may be positively influenced by salinity, total alkalinity, and acidity of the seawater. In this study we tested the combined effects of changes in salinity, total alkalinity, and acidity of Mediterranean seawater due to dilution with deionized water and bubbling with $\mathrm{CO}_{2}$ gas on the intensity of electrical sparks discharged into the treated seawater in a laboratory experimental setup. These changes also simulate the effects of changes in salinity and seawater $\mathrm{pH}$ in the Levantine Sea due salinization, mediated by global warming and the erection of the Aswan High Dam (AHD), and ongoing ocean acidification due to the anthropogenic increase in atmospheric $\mathrm{CO}_{2}$ and its absorption in the surface of the oceans. The experimental results suggest that since the 1960's cloud to sea surface lightning intensity in the Levantine may have increased by ca. $12 \%$ and by as much as $32 \%$ by the end of the 21 st century.

Keywords: Lightning intensity, Mediterranean Sea, Levantine, Salinization, Ocean acidification, Total alkalinity

\section{Introduction}

Since the beginning of the industrial revolution, the Mediterranean Sea has been undergoing rapid changes in its physical and chemical ecology, due to global and regional pressures. The construction of the Aswan High Dam (AHD) caused the annual mean discharge of Nile water into the Mediterranean Sea to decrease gradually from $\sim 40$ to $\sim 4 \mathrm{~km}^{3} \cdot \mathrm{yr}^{-1}$ [1] over a four year period after its completion in 1964 [2]. The Dam significantly affected various aspects of the ecological system in the eastern basin of the Mediterranean Sea (Levantine Sea), primarily as a result of the significant reduction in nutrient supply during the seasonal Nile floods (e.g. Nixon [3]. The spatial extent of the Nile flood plumes is considered to have affected the salinity and productivity of the Levantine Sea (e.g. Sharaf [2] and Suari [4]). According to a modeling study, the significant reduction of freshwater input from the Nile into the Mediterranean, on the order of $6.5 \mathrm{~cm} \cdot \mathrm{yr}^{-1}$ over the entire area of the Sea [5], is considered to have had profound effects on the thermohaline circulation and water mass characteristics of the Mediterranean Sea in general [6]. Thus, the model results showed that the salinity in the upper $0-20 \mathrm{~m}$ in the Levantine Surface
Water (LSW) mass increased from $\sim 38.95$ pre damming to $~ 39.1$ less than 10 years post damming after which it started approaching steady state. These results suggest the majority of a 0.15 increase in salinity of Levantine surface water occurred within the period 1965-1975. However, this model did not consider the effects of global warming on the evaporation rates in the Levantine Sea (LS). In addition, it should be noted that the expansion of the Suez Canal in 1980, by a factor of 3 relative to its previous average cross-section, together with global warming caused an increase of Red Sea water discharge into the Mediterranean Sea to as much as $65 \mathrm{~km}^{3} \cdot \mathrm{yr}^{-1}$ [7]. This volume of discharged water, which has a salinity of ca 42 PSU and total alkalinity of $2618 \mu \mathrm{mol} \cdot \mathrm{kg}^{-1}$, may likely have an effect on the salinity and alkalinity budget of the Easter Mediterranean Sea, however to the best of our knowledge this has not been considered in any study so far. Seasonal measurements in the open waters of the eastern LS during the period 1979-2014 have shown that the salinity of the LSW increased from $\sim 39.2$ to 39.5 , while the temperature increased from $\sim 24$ to $28^{\circ} \mathrm{C}$ [8]. Thus, since the damming of the Nile in 1964 , the overall increase in the salinity of the LSW was at least 0.4 PSU. Bialik 
\& Sisma-Ventura [9] estimated based on available measurements of salinity in the surface water of the Eastern Mediterranean basin since 1947 until 2010 that the wintertime (October-March or Q1 and Q4 as reported in Bialik \& Sisma-Ventura) salinity increased from 38.7438.87 pre AHD (1947-1964) to 39.08-39.40 in the post AHD period (1980-2010). Accordingly, the resulting increase in total alkalinity (TA) according to Bialik \& Sisma-Ventura [9] during the wintertime over the same period was 2594-2596 to $2616-2635 \mu \mathrm{mol} \cdot \mathrm{kg}^{-1}(\Delta \mathrm{TA}=$ $\left.41 \mu \mathrm{mol} \cdot \mathrm{kg}^{-1}\right)$. Based on a reconstructed record of DIC in LS seawater from measurements of $\delta^{13} \mathrm{C}$ in eastern Mediterranean Vermetid reef cores, estimated TAs (from salinity), they calculated the change in $\mathrm{pH}$ over the same period, which yielded an overall decrease in the $\mathrm{pH}$ of LSW from $\sim 8.1$ to $\sim 8$ at a rate of $-0.022 \pm 0.002$ decade $^{-1}$. This rate is slightly higher than the rate of acidification in oceanic surface waters due to the anthropogenic increase in atmospheric $\mathrm{CO}_{2}[10,11]$. In our previous studies we showed that the intensity of lightning discharged into the oceans may be influenced by the salinity, $\mathrm{pH}$ and TA of the receiving sea surface water [12,13] and Silverman [14]. In these studies we suggested that the apparently high density of superbolt activity [15] in the Mediterranean Sea (ca. 24\% of the global activity) in general and specifically in the LS, may well be related to the relatively high salinity and TA of these waters. Where, superbolts are high energy cloud to ground electrical discharges with peak currents $>100 \mathrm{kA}$ [16]. These conclusions were based on laboratory generated electrical sparks that were discharged into the experimental solutions as detailed in the methods section below. Based on these experiments it was shown that the Lightning Flash Intensity (LFI) in our experimental setup, is positively correlated with the concentration of $\mathrm{NaCl}$ in de-ionized water solutions [12], negatively correlated with the $\mathrm{pH}$ and positively correlated with the TA of LS seawater of [13,14]. The salinization and corresponding increase in TA due to the AHD and increased evaporation due to global warming, coupled with the ongoing process of OA in the LS could have caused lightning intensity in this region to increase. In this study we investigate the dependence of the laboratory generated spark intensity (LFI) on the variations in salinity, TA and $\mathrm{pH}$ of LS seawater obtained by their dilution with de-ionized water and $\mathrm{CO}_{2}$ gas bubbling. Based on these experimental results we suggest that the cloud to sea surface lightning discharge intensity in the LS may have already increased by as much as $12 \pm$ $1.4 \%$ due to the combined effects of the AHD, global warming and $\mathrm{OA}$ on salinity, TA and $\mathrm{pH}$.

\section{Materials and Methods}

LFI measurements were performed using the same experimental setup described by Asfur and Silverman [12-14]. However, in this study we report the integrated value of LFI over the entire spectral range (150-900 nm) in $\mu \mathrm{W} \cdot \mathrm{cm}^{-2}$ following factory calibration. The day before each experiment we collected a fresh stock of filtered seawater that was subsampled consecutively for each treatment into a $2 \mathrm{~L}$ graded Erlenmeyer Flask. After this we added to each flask varying volumes of distilled water as follows $-25,50,70,100,125$ and 150 $\mathrm{mL}$, respectively. In addition, we added $\mathrm{NaOH}(1 \mathrm{~N})$ to three more flasks of Mediterranean seawater that were diluted by addition of 50 , 100 and $150 \mathrm{~mL}$ of deionized water. The volume of $\mathrm{NaOH}$ added was estimated in order to compensate for the loss of TA due to dilution back to the original TA. The flasks were left in the lab overnight (24 hours) while stirring gently with magnetic stirrers in order to accelerate the equilibration of $\mathrm{CO}_{2}$ in the experimental solution with ambient atmospheric $\mathrm{CO}_{2}$. The following day, the solutions were subsampled into brown glass bottles through a $0.45 \mu \mathrm{m}$ syringe GFF filter for later analysis in the lab of Total Alkalinity (TA), Dissolved Inorganic Carbon (DIC) and density. The remaining solution was poured into our custom made glass aquarium and with a hole in the side for inserting the spectrometer fiber-optic sensor $1 \mathrm{~cm}$ above the waterline. Immediately afterwards, the aquarium was placed in the lightning cabinet on a magnetic stirrer and the initial values of $\mathrm{pH}$, temperature and conductivity of the experimental solutions were measured with a handheld WTW multi-meter (MultiLine Multi 3630 IDS), while gently stirring the solution with a rotating magnetic bar. The $\mathrm{pH}$ was measured with a combination glass electrode and thermistore, which was calibrated at the beginning of every experiment day with WTW buffer solutions ( $\mathrm{pH} 4.01 \pm 0.02$ and $7.00 \pm 0.03$ ). The specified precision of the electrode is $\pm 0.004 \mathrm{pH}$ units. Conductivity was measured with a WTW-IDS digital conductivity cell TetraCon 925 electrode for universal applications $\left(1 \mu \mathrm{S} \cdot \mathrm{cm}^{-1}-2000 \mathrm{mS} \cdot \mathrm{cm}^{-1}\right)$ with a $\pm 0.5 \%$ of value accuracy or for Mediterranean seawater with a conductivity of ca. $56 \mathrm{mS} \cdot \mathrm{cm}^{-1}$, the accuracy is $\pm 0.3 \mathrm{mS} \cdot \mathrm{cm}^{-1}$. After these measurements were taken, turning off the magnetic stirrer and closing the cabinet, we activated the power supply to generate electrical sparks for a period of $20 \mathrm{sec}$ and recording the spectral emission every $0.2 \mathrm{sec}$. The spectral emissions of the sparks were measured as described above. After the initial measurement of the experimental solutions we gently bubbled them for short periods $(<2$ sec) with $\mathrm{CO}_{2}$ gas (99.999\%) to produce carbonic acid that caused a reduction in $\mathrm{pH}$ from its initial value of ca. $\mathrm{pH}=8.2$ and $\sim 8.5$ for $\mathrm{NaOH}$ treatments. After each bubbling period, the solution was gently stirred as described above to homogenize it, and $\mathrm{pH}$ was measured simultaneously until kinetic equilibrium was deemed to be attained when $\Delta \mathrm{pH} / \Delta \mathrm{t}<+0.001 / 5 \mathrm{sec}$. Measurements of conductivity and temperature were also recorded for each bubbling step. The $\mathrm{pH}$ values that were tested by $\mathrm{CO}_{2}$ bubbling addition were in the range (6.5-8.5 at $25^{\circ} \mathrm{C}$ ). After each bubbling, the power supply was activated and the emission spectra of the generated sparks were repeatedly measured as described above. After the $\mathrm{pH}$ reached 6.5 the experiment was stopped and water samples were taken from the aquarium for later analysis in the lab of TA, DIC and density as described above. Analyses of TA samples were done with a Methrom 785 Titrino Plus potentiometric titration system with $\sim 0.05 \mathrm{~N} \mathrm{HCl}$, based on the analytical procedures and calculations described by Sass and Ben-Yaakov [17]. TA measurements were calibrated and standardized using seawater CRMs from A. Dickson's lab [18]. DIC was measured by acidifying and stripping the $\mathrm{CO}_{2}$ gas from a subsample in a stream of high grade $\mathrm{N}_{2}$ gas (99.999\%) using a custom made system Aerica (Marianda) gas distillation system. The distillation system transported the mixture to a LICOR 7000 IR absorbance sensor that integrated the partial pressure of $\mathrm{CO}_{2}$ over the entire measurement cycle. Replicate measurements were made $(n=3)$ for each sample and had an average precision of less than $\pm 2 \mu \mathrm{mol} \cdot \mathrm{kg}^{-1}$. The system was adjusted for drift every 4 sample measurements with a Dickson CRM (Op. Cit.). Laboratory seawater density measurements were made with a 6 digit accuracy Anton Paar 
DMA-5000 densitometer and converted to salinity values with the measurement temperature using the equation of state for seawater from the $19^{\text {th }}$ edition of standard methods [19]. In the presentation of the LFI versus the $\mathrm{pH}$ measurements, we adjust the $\mathrm{pH}$ to a constant temperature of $25^{\circ} \mathrm{C}$ using the formula from Gieskes [20].

\section{Results}

In general, our experimental results show that there is a strong positive correlation between salinity and TA in the dilution treatments (MSW+DIW line in Figure 1a), while for the treatments where the TA of the experimental solution was adjusted with $\mathrm{NaOH}$ after dilution, the TA diverges increasingly with decreasing salinity and has a relatively constant value of ca. $2625 \mu \mathrm{mol} \cdot \mathrm{kg}^{-1}(\mathrm{MSW}+\mathrm{DIW}+\mathrm{NaOH}$ line in Figure 1a). In our experiments, we diluted the initial Mediterranean seawater to a minimum salinity and TA of ca. 36.4 and $2631 \pm 11 \mu \mathrm{mol} \cdot \mathrm{kg}^{-1}$ (Figure $1 \mathrm{~b}$ ), respectively. This range of variation also includes the range in which the TA and salinity of the LS increased from the Pre AHD (PAHD) period to the period 19802010 after the erection of the AHD (AAHD) according to Bialik and Sisma-Ventura [9]. It should be noted that this overall period (PAHDAAHD) includes changes in salinity and TA of LS seawater that resulted from the combined effects of the AHD and global warming.
The LFI in our experiments was positively influenced by the TA and $\mathrm{pH}$ of the seawater (Figure 1b). Furthermore, as displayed in Figure 1a, the changes in TA below the value of untreated LS seawater $(2622$ $\pm 8 \mu \mathrm{mol} \cdot \mathrm{kg}^{-1}$ ) were caused by dilution with de-ionized water, which decreased the salinity according to the MSW+DIW line in Figure 1a. However, despite the decrease in salinity due to dilution, the LFI was the highest for the experiments in which the TA of the solutions was adjusted by addition of $\mathrm{NaOH}$ to a value of $2631 \pm 11 \mu \mathrm{mol} \cdot \mathrm{kg}^{-1}$. These results suggest that the effect of varying TA overrides the influence of salinity on LFI as shown in Silverman [14]. However, unlike the dependence of LFI on TA in Silverman [14], where $\Delta \mathrm{LFI} / \Delta \mathrm{TA}=$ $-0.03 \% / 1 \mu \mathrm{mol} \cdot \mathrm{kg}^{-1}$ in relative change units compared to the highest value, in this study the $\Delta \mathrm{LFI} / \Delta \mathrm{TA}=-0.4 \% / 1 \mu \mathrm{mol} \cdot \mathrm{kg}^{-1}$. It should be noted that in Silverman [14], the TA was adjusted by additions of strong acid $(\mathrm{HCl})$ or strong base $(\mathrm{NaOH})$, which had very little effect on the conductivity of the solution. Therefore, it is concluded that LFI is less sensitive to changes in TA without corresponding changes in salinity due to dilution. The decoupling of the influence of salinity on LFI from TA is clearly demonstrated in Figure 1c. Where, despite the decrease in salinity due to dilution, adjustment of the TA back to its initial value by addition of $\mathrm{NaOH}$ has an increasingly stronger influence on LFI with decreasing salinity.
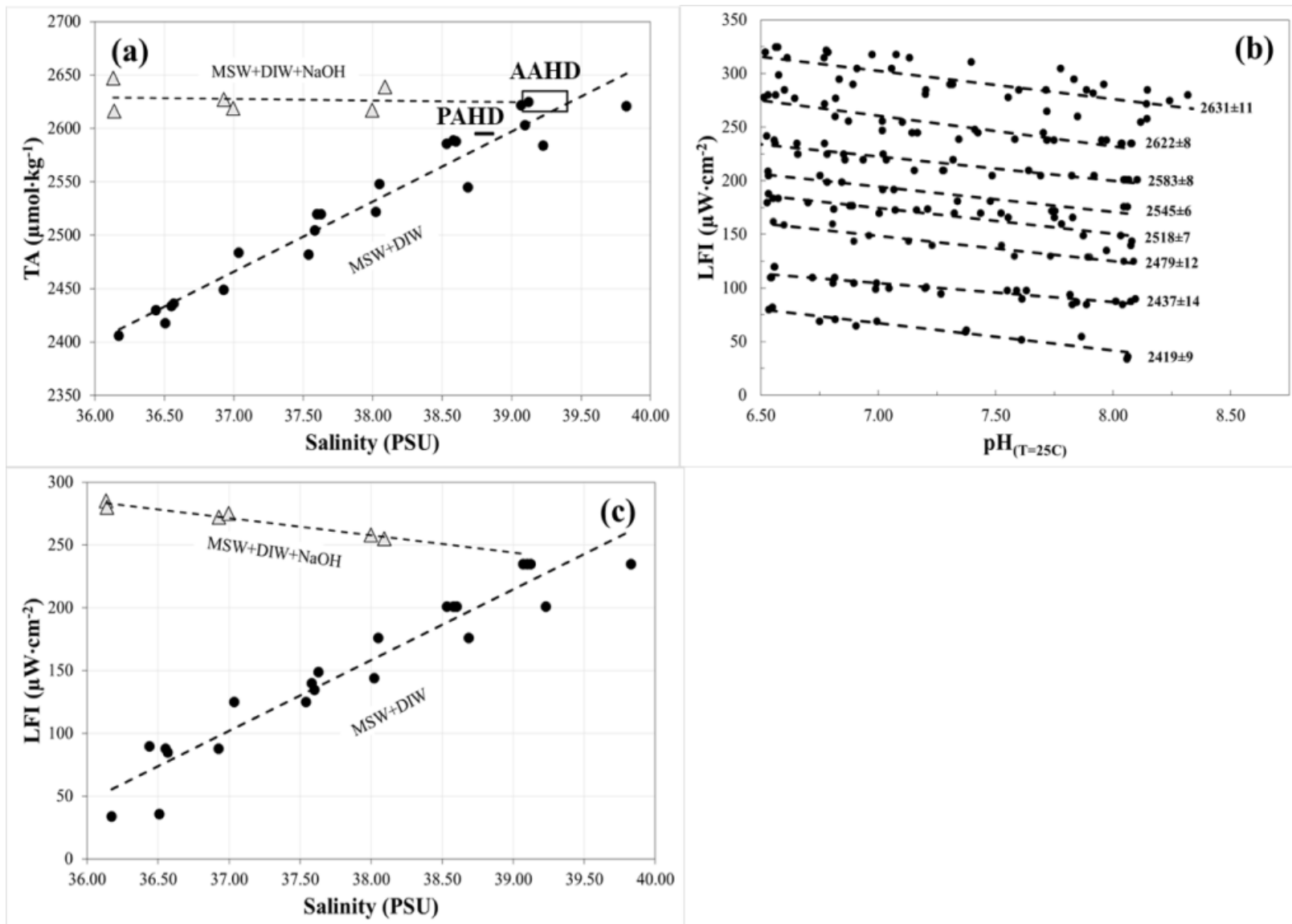

Figure 1: (a) Initial values of TA plotted versus corresponding values salinity values for all experimental solutions. The black rectangles indicate the range of salinity and TA values during the wintertime (October-March) over the period 1947-1964, before the erection of the Aswan High Dam (PAHD), and during the period 1980-2010 after the erection of the Aswan High Dam (AAHD) according to Bialik and Sisma-Ventura (2016); (b) Increase of LFI as a function of $\mathrm{pH}$ at constant Total Alkalinity (TA) in all of the experimental solution before and during CO bubbling. The lines of constant total alkalinity are linear best fits ( $\mathrm{LFI} v \mathrm{pH}_{(\mathrm{T}=25 \mathrm{C})}$ ) of experimental solutions with similar initial TA measured on different days; (c) Decoupling of the positive dependence of LFI on salinity by adjustment of the TA in experimental solutions with $1 \mathrm{~N} \mathrm{NaOH}$ addition to the original Mediterranean seawater TA after dilution with 50,100 and 150 mL deionized water (grey triangles, see Figure 1a). 


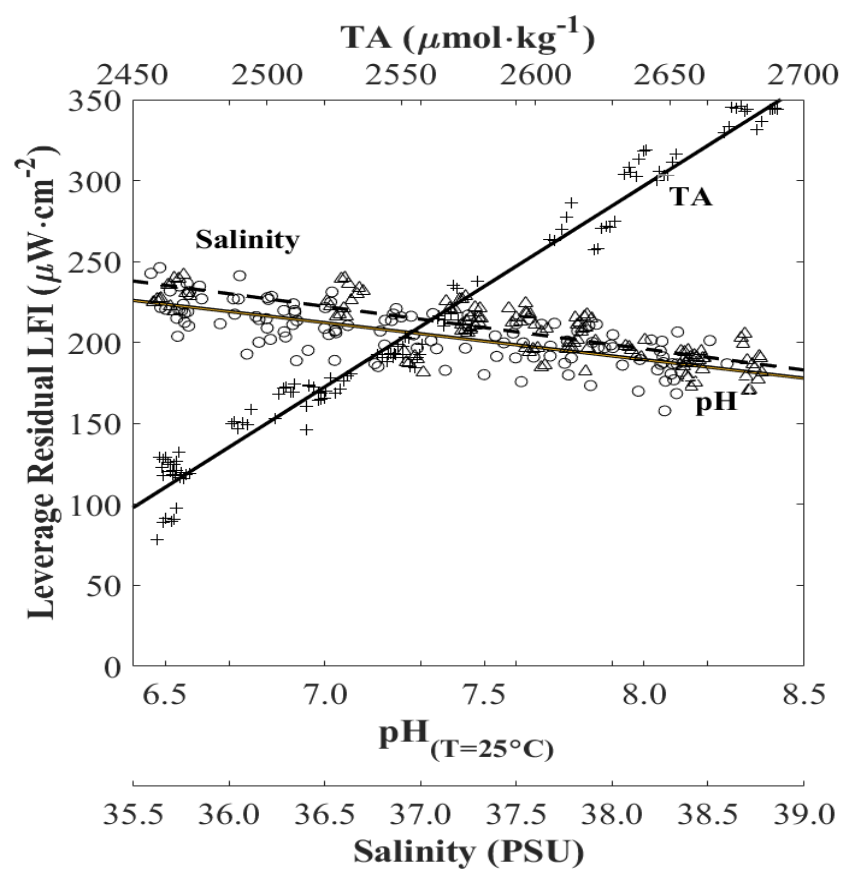

Figure 2: Leverage residuals of salinity (empty triangles), $\mathrm{pH}$ adjusted to $25^{\circ} \mathrm{C}$ (empty circles) and total alkalinity (TA, + signs) for a multi variate linear fit model of LFI $=a_{0} \cdot S+$ $a_{1} \cdot p H+a_{2} \cdot T A+C$. Where, $a_{0}=-2.49 \pm 2.64(\mathrm{p}=0.35), a_{1}=-23.85 \pm 4.88(\mathrm{p}<0.0001), a_{2}=0.825$ $\pm 0.031(\mathrm{p}<0.0001)$ and $C=-1629 \pm 116(\mathrm{p}<0.0001), \mathrm{n}=137, \mathrm{R}^{2}=0.85$.

The multivariate linear fit model of LFI as a function the experimental conditions of salinity, $\mathrm{pH}$ and $\mathrm{TA}$, yields significant fits for $\mathrm{pH}$ and $\mathrm{TA}$ and non-significant for salinity (Figure 2). Furthermore, the leverage residuals for LFI indicate a significant positive relation with TA as expected [14], a significant negative relation of LFI with $\mathrm{pH}$ as expected [13] and an unexpected negative yet insignificant relation with salinity [12]. It should be noted that in the Asfur [12] study, the dependence of LFI on salinity was established for a $\mathrm{NaCl}$ solutions with increasing concentration $(0-7 \mathrm{~g} / \mathrm{L})$. This solution should not have total alkalinity by definition and therefore these results are not comparable to the results of this study, where the effect of salinization on LFI in the current experiments apparently acts through the changes in TA of seawater and not through the salinity.

\section{Discussion and Conclusion}

To date, with the exception of Asfur et al. [13], global change studies have only considered the effect of warming on lightning flash frequency and the global distribution of lightning activity [21-24] and Williams [23] based their predictions of increased lightning frequency on theoretical considerations, while Reeve \& Toumi [22] and Romps [24] based their predictions on observed relations between spatial variations of flash frequency, air temperature and precipitation derived from satellite measurements over an annual cycle. Furthermore, none of these studies considered the effects of warming on lightning flash intensity. In fact, only relatively recently, it has become possible to estimate the intensities (peak current) of cloud to ground lightning discharges on a regional and global scale [15]. Therefore, it is still difficult to determine the effects of global warming on the intensity of lightning flashes with any reasonable degree of certainty from observations. The discharge of cloud to ground lightning is a result of numerous processes that are influenced differently by global warming. The main process considered to cause the increase in lightning flash frequency due to global warming is the increase in Convective Available Potential Energy, i.e. CAPE theory [24]. In the oceans, sea surface temperature (SST) warming has been shown to increase deep convection in the atmosphere above [25], i.e. increase in CAPE, and therefore it could be expected that the lightning flash frequency over the oceans would increase accordingly. In the Mediterranean Sea for examples, the relation between spatially varying (SST) and lightning flash frequency was demonstrated by [26]. Interestingly, according to their analysis the lightning flash frequency increases with SST at a rate of $\sim 20 \%{ }^{\circ} \mathrm{C}^{-1}$, which is quite similar to the rate determined by Romps [24] for the continental USA of $12 \%{ }^{\circ} \mathrm{C}^{-1}$. This suggests that CAPE has a similar effect on lightning frequency over land and sea. Yet, the observed total frequency of lightning over the land is much greater than that observed over the oceans throughout an entire annual cycle over the entire surface of the Earth (e.g. Price, 2009), perhaps calling into question the validity of the CAPE theory. It seems that the underlying assumption for the CAPE theory is that the electrical discharge threshold is constant and dependent only on the dielectric properties of the atmosphere between the cloud base and the ground. Thus, it is possible to suggest, given that the amount of accumulated charge in the cloud base is finite and thus the intensity can increase at the expense of frequency decrease. Asfur [12,13] and Silverman et al. (2021) [14] suggested that chemical properties of seawater, including salinity, $\mathrm{pH}$ and TA, may affect the lightning flash intensity. This could explain the apparent global distribution of lightning flash frequency with higher frequency over the continents (10-90 flashes per second) and significantly lower frequency over the oceans (5-10 flashes per second) [27]. In contrast, nearly $95 \%$ of superbolts, which are $100-$ 1000 times more energetic than regular lightning bolts, occur over the oceans [15]. Where, it should be noted that $24 \%$ of the total number of superbolts observations included in the Holzworth et al. [15] dataset (2010-2018), occurred over the Mediterranean Sea. In light of these facts, we suggest that the intensity of cloud to sea surface electrical discharges is higher over the sea than over the land at the expense of lower flash frequency. Perhaps conducting electrical energy balances over the land and sea could provide further insight. Present and future SST warming of Mediterranean seawater could increase convection and charge accumulation in thunder clouds, potentially resulting in increased lightning flash frequency [26]. Conversely, past and future salinization and acidification of Mediterranean surface waters could have potentially increased and continue to increase the intensity of lightning over the sea. The potential increase in lightning intensity due to salinization and acidification of seawater could offset the potential increase in lightning flash frequency due to SST warming and vice versa. Nonetheless, the results of this study suggest that lightning intensity over the Mediterranean may have increased substantially and will continue to do so, primarily in response to the erection of the AHD (salinization), global warming (salinization + CAPE) and ocean acidification. As stated above, the erection of the AHD in the 1960 's caused an increase of 0.15 PSU in the sea surface salinity of the Mediterranean over the following decade, with a corresponding increase in TA of ca. $10 \mu \mathrm{mol} \cdot \mathrm{kg}^{-1}$. Together with global warming and the increased evaporative flux from the Mediterranean Sea surface, 
the salinity until the present has increased by ca. 0.45 PSU since the erection of the AHD. Therefore, the overall salinization of Levantine Surface Water (LSW) increased the TA by ca. $30 \mu \mathrm{mol} \cdot \mathrm{kg}^{-1}$. Finally, over the same period, ongoing ocean acidification is estimated to have decreased the $\mathrm{pH}$ of the LSW by ca 0.1 . Thus, the overall effect of these changes on LFI in the LS, based on our experimental results, is an increase of $12 \pm 1.4 \%$ relative to the pre 1960's LFI. Assuming that salinization and acidification of LSW will continue at current trends, the LFI will increase relative to the pre 1960's by $23 \pm 2.9 \%$ in 2050. Alternatively, according to the predicted changes in SSS of the Mediterranean Sea (ca. +0.9 PSU since ADH), based on the ensemble of climate change scenario simulations according to Adloff et al. [28] and current trend in OA, LFI will increase by ca. $32 \%$ by 2100. However, it should be noted that a more recent coupled oceanatmosphere ensemble modeling study suggests that increased flow of relatively fresher northern Atlantic Ocean water through the Gibraltar Strait into the Mediterranean will substantially subdue current salinization trends by the end of the $21^{\text {st }}$ century [29]. Regardless of these predictions and in light of our experimental results, the fact that the Mediterranean Sea is a hotspot for superbolt activity and climate change, it is important to follow, not only trends in lightning flash frequency, but also lightning intensity.

\section{Acknowledgement}

The authors would like to thank the Technical team at the Ruppin academic center Mr. Yosi Moas and Mr. Asher Azoli. Special thanks to Dani Ramot (Fritzi) from IOLR for his invaluable help with the electronical aspects of the experimental setup, and to Deborah BurdVilanova from IOLR for her help in the laboratory analysis of seawater samples. This work was supported by the Research Authority Ruppin academic center.

\section{Data Availability Statement}

All experimental data presented in this report are available in the supplementary online material and the Mendeley Data repository at https://data.mendeley.com/datasets/nfyrb4hwhd/1

\section{References}

1. Halim Y, Rizkalla S, Morcos SA, El-Sayed MK (1995) The impact of the Nile and the Suez Canal on the living marine resources of the Egyptian Mediterranean waters. Effects of Riverine Inputs on Coastal Ecosystems and Fisheries Resources, (349) 19.

2. Sharaf El Din SH (1977). Effect of the Aswan High Dam on the Nile flood and on the estuarine and coastal circulation pattern along the Mediterranean Egyptian coast. Limnology and Oceanography 22: 194-207.

3. Nixon SW (2003) Replacing the Nile: are anthropogenic nutrients providing the fertility once brought to the Mediterranean by a great river? AMBIO: A Journal of the Human Environment 32: 30-39. [crossref]

4. Suari Y, Brenner S (2015) Decadal biogeochemical history of the south east Levantine basin: Simulations of the river Nile regimes. Journal of Marine Systems 148: 112-121.

5. Skliris N, Sofianos S, Lascaratos A (2007). Hydrological changes in the Mediterranean Sea in relation to changes in the freshwater budget: a numerical modelling study. Journal of Marine Systems 65: 400-416.

6. Skliris N, Lascaratos A (2004) Impacts of the Nile River damming on the thermohaline circulation and water mass characteristics of the Mediterranean Sea. Journal of Marine Systems 52: 121-143.

7. Biton E (2020) Possible implications of sea level changes for species migration through the Suez Canal. Scientific Reports 10: 1-16.
8. Ozer T, Gertman I, Kress N, Silverman J, Herut B (2017). Interannual thermohaline (1979-2014) and nutrient (2002-2014) dynamics in the Levantine surface and intermediate water masses, SE Mediterranean Sea. Global and Planetary Change 151: 60-67.

9. Bialik OM, Sisma-Ventura G (2016) Proxy-based reconstruction of surface water acidification and carbonate saturation of the Levant Sea during the Anthropocene. Anthropocene 16: 42-53.

10. Sisma-Ventura G, Bialik OM, Yam R, Herut B, Silverman J (2017). $\mathrm{pCO}_{2}$ variability in the surface waters of the ultra-oligotrophic Levantine Sea: Exploring the air-sea $\mathrm{CO}_{2}$ fluxes in a fast warming region. Marine Chemistry 196: 13-23.

11. Bates NR, Astor YM, Church MJ, Currie K, Dore JE, et al. (2014). A Time-Series View of Changing Surface Ocean Chemistry Due to Ocean Uptake of Anthropogenic $\mathrm{CO}_{2}$ and Ocean Acidification. Oceanography 27: 126-141.

12. Asfur M, Price C, Silverman J, Wiskerman A (2020a) Why is lightning more intense over the oceans? Journal of Atmospheric and Solar-Terrestrial Physics.

13. Asfur M, Silverman J, Price C (2020b) Ocean acidification may be increasing the intensity of lightning over the oceans. Nature Sc. Rep.

14. Silverman J, Price C, Asfur M (2021). The possible effect of seawater total alkalinity on lightning flash intensity - An experimental approach. Geophysical Research Letters

15. Holzworth RH, McCarthy MP, Brundell JB, Jacobson AR, Rodger C J (2019) Global Distribution of Superbolts. J. Geophys. Res. Atmos. 124: 9996-10005.

16. Peterson M, Kirkland MW (2020) Revisiting the Detection of Optical Lightning Superbolts. Journal of Geophysical Research: Atmospheres 125.

17. Sass E, Ben-Yaakov S (1977) The carbonate system in hypersaline solutions: Dead Sea brines. Mar Chem. 5: 183-199.

18. Dickson AG, Afghan JD, Anderson GC (2003) Reference materials for oceanic CO2 analysis: a method for the certification of total alkalinity. Mar Chem. 80: 185-197..

19. Fofonof NP, Millard RC (1983) Algorithms for computations of fundamental properties of seawater. Prise, France, UNESCO. (Technical Papers in Marine Science.) 44

20. Gieskes JM (1969). Effect of Temperature on the pH of Seawater. Limnology and Oceanography 14: 679-685.

21. Price C, Rind D (1994). Possible implications of global climate change on global lightning distributions and frequencies. Journal of Geophysical Research: Atmospheres 99(D5): 10823-10831.

22. Reeve N, Toumi R (1999). Lightning activity as an indicator of climate change. Quarterly Journal of the Royal Meteorological Society 125: 893-903.

23. Williams ER (2005) Lightning and climate: A review. Atmospheric research, 76: 272287

24. Romps DM, Seeley JT, Vollaro D, Molinari J (2014). Projected increase in lightning strikes in the United States due to global warming. Science, 346: 851-854.

25. Xie SP (2020) Ocean warming pattern effect on global and regional climate change. AGU advances 1 .

26. Kotroni V, Lagouvardos K (2016). Lightning in the Mediterranean and its relation with sea-surface temperature. Environmental Research Letters 11.

27. Price C (2009) Thunderstorms, lightning and climate change. In Lightning: principles, instruments and applications, pg: 521-535. Springer, Dordrecht.

28. Adloff F, Somot S, Sevault F, Jordà G, Aznar R, et al. (2015). Mediterranean Sea response to climate change in an ensemble of twenty first century scenarios. Climate Dynamics 45: 2775-2802.

29. Soto-Navarro J, Jordá G, Amores A, Cabos W, Somot S, et al. (2020). Evolution of Mediterranean Sea water properties under climate change scenarios in the MedCORDEX ensemble. Climate Dynamics 54: 2135-2165.

\section{Citation:}

Asfur M, Silverman J (2021) The Potential Effect of Anthropogenic Salinization and Ocean Acidification on Lightning Flash Intensity Over the Mediterranean Sea. Geol Earth Mar Sci Volume 3(4): 1-5. 